\title{
A individuação e a máquina: leitura deleuzeana de Simondon
}

\author{
Bruno Vasconcelos de Almeida ${ }^{1}$
}

\begin{abstract}
Resumo: Este trabalho objetiva investigar duas questões no plano das ressonâncias entre Simondon e Deleuze. A primeira diz respeito aos elementos conceituais que dispomos para pensar a individuação psíquica e coletiva, isto é, os modos de produção de subjetividade implicados com a processualidade dos acontecimentos. A segunda diz respeito às linhas de força que desenham os processos subjetivos desencadeados nos encontros entre homens, meios e objetos técnicos. No movimento de aproximação entre as questões, deriva-se a pergunta pela problemática da individuação psíquica, coletiva e maquínica. Neste sentido, o artigo trabalha algumas articulações entre objetos técnicos e cultura, entre tecnologias e máquinas, propondo, ainda, uma análise do vídeo de Chris Cunningham (1999), em parceria com a cantora Björk, intitulado 'The Erotic Life of Machine'.
\end{abstract}

Palavras-chave: Individuação, Máquina, Deleuze, Simondon, Tecnologia.

Abstract: This paper aims to investigate two issues in terms of resonances between Simondon and Deleuze. The first concerns the conceptual elements that we have to think about the psychic and collective individuation, i.e. the subjectivity production pathways involved with the processuality of events. The second refers to the power lines that draw the subjective processes triggered by meetings among men, means and technical objects. From the approach move between the issues derives the question by the problematic of psychic, collective and machinic individuation. This way, the paper deals with some links between technical objects and culture, between technology and machinery, proposing even a Chris Cunningham video (1999) analysis, in partnership with the singer Björk, entitled "The Erotic Life of Machine".

Keywords: Individuation, Machine, Deleuze, Simondon, Technology.

\section{A individuação e a máquina: leitura deleuzeana de Simondon}

Este trabalho objetiva investigar duas questões no plano das ressonâncias entre Simondon e Deleuze. A primeira diz respeito aos elementos conceituais que dispomos para pensar a individuação psíquica e coletiva do ponto de vista da clínica psicológica, isto é, os modos de produção subjetiva implicados com a processualidade dos acontecimentos. A segunda diz respeito às maneiras de afetação entre homens e máquinas, afetação esta designada como subjetividade maquínica, vale dizer, as linhas de força que desenham os processos subjetivos desencadeados nos encontros entre homens, meios e objetos técnicos. No movimento de aproximação e choque da primeira com a segunda questão, deriva-se a pergunta pela problemática da individuação psíquica, coletiva e maquínica. Neste sentido,

${ }^{1}$ Pós-doutor em Filosofia (UFMG). Doutor e mestre em Psicologia Clínica (PUC-SP). Professor Adjunto IV (PUC Minas). Coordenador de Pesquisa do Curso de Psicologia. Psicólogo. Membro do Núcleo de Estudos do Pensamento Contemporâneo (NEPC/FAFICH/UFMG). E-mail: brunovasconcelos@pucminas.br. 
percorre-se algumas articulações entre objetos técnicos e cultura, bem como entre tecnologias e máquinas, para terminar na análise do vídeo de Chris Cunningham (1999) com música e participação da cantora Björk, intitulado 'The Erotic Life of Machine'.

\section{A leitura deleuzeana de Simondon}

Para pensar as questões enunciadas acima, percorro a leitura que Deleuze (1925 1995) faz da obra de Gilbert Simondon (1924 - 1989). Nos trabalhos de Deleuze encontramse quatro passagens que remetem diretamente a Simondon: O Indivíduo e sua Gênese FísicoBiológica (1966), Síntese Assimétrica do Sensível/Diferença e Repetição (1968), a nona e a décima quinta séries de Lógica do Sentido (1969) e A Geologia da Moral (Quem a terra pensa que é?) de Mil Platôs 1 (1980). Nestes casos, a referência é direta, Deleuze trata de Simondon, com fascínio, mas ao mesmo tempo sinalizando algumas diferenças.

Em O Indivíduo e sua Gênese Físico-Biológica (1966), a questão prévia da individuação é a existência de um sistema metaestável definido por uma disparação entre duas ordens de grandeza, duas escalas de realidades díspares, onde não há comunicação interativa; ao contrário, existe dissimetria, energia potencial e diferença de potencial. Neste texto, Deleuze afirma que o metaestável é definido como ser pré-individual, provido de singularidades. Singular sem ser individual, eis o estado do ser pré-individual (DELEUZE, 2006, p.118). A disparidade (a categoria do problemático) é, portanto, o primeiro momento do ser, singular e prévio à individualidade. Trata-se da distinção entre singularidade e individualidade, que terá, por sua vez, inúmeros desdobramentos no pensamento de Deleuze. A ressonância, outro conceito importante de Simondon, retomado por Deleuze, aparece como o modo mais primitivo de comunicação entre realidades de ordens diferentes (DELEUZE, 2006, p.119).

No trabalho de Deleuze encontram-se ainda outras ideias em torno da individuação: a categoria do 'problemático' é definida como momento do ser e primeiro momento préindividual. A individuação é organização de uma solução, isto é, uma resolução para um sistema objetivamente problemático. Por um lado, essa resolução apresenta-se como ressonância interna, modo primitivo de comunicação entre realidades de ordens diferentes 
(Deleuze diz que a ressonância terá grande importância no domínio da afetividade). Por outro, essa resolução é informação, clara referência à cibernética e à teoria da significação.

[...] Simondon não quer ater-se a uma determinação biológica da individuação propriamente, mas precisar níveis cada vez mais complexos: assim, há uma individuação propriamente psíquica, que surge, precisamente, quando as funções vitais já não bastam para resolver os problemas postos ao vivente, e quando uma nova carga de realidade pré-individual é mobilizada numa nova problemática, em um novo processo de solução. E o psiquismo, por sua vez, abre-se a um coletivo trans-individual. (DELEUZE, 2006, p.120).

Simondon e Deleuze apontam para níveis cada vez mais complexos de individuação: biológica, psíquica, coletiva, trans-individual. A individuação, nos três últimos níveis, sinaliza, para Deleuze, a possibilidade de se pensar a subjetivação sem o indivíduo, ou melhor, uma subjetivação sem sujeito, radicalizada no processo através do qual tudo é fluxo, dinamismo organizador, máquina de acoplagem. As máquinas colocam em jogo, e mais a frente voltaremos a isto, novas maneiras de se pensar o desejo, e portanto, outra teoria da subjetividade.

Deleuze refere que o pré-individual permanece associado ao indivíduo, fonte de estados metaestáveis futuros, em novos agenciamentos que levam em consideração a ressonância interna e a informação.

Assinalamos um estranhamento com a assertiva de que há ética na medida em que há informação. Quando o indivíduo se separa da realidade pré-individual, recusa-se a comunicar e ocorre perda de informação (desequilíbrio no sistema, se a ressonância é interrompida).

Em Diferença e Repetição (Síntese Assimétrica do Sensível), Deleuze aborda o conceito de disparidade (disparação) como um estado de diferença infinitamente desdobrada.

\begin{abstract}
A disparidade, isto é, a diferença ou a intensidade (diferença de intensidade) é a razão suficiente do fenômeno, a condição daquilo que aparece. Com sua turmalina, Novalis está mais próximo das condições do sensível do que Kant com o espaço e o tempo. A razão do sensível, a condição daquilo que aparece não é o espaço e o tempo, mas o desigual em si, a disparação tal como é ela compreendida e determinada na diferença de intensidade, na intensidade como diferença. (DELEUZE, 1988, p.356-357).
\end{abstract}

Há um primado da disparação em relação à oposição, às relações de oposição. A individuação não é a diferenciação. O processo contém disparação, individuação e diferenciação. Do mesmo modo como não se tem ou não se é o eu universal, não se tem ou 
não se é o objeto universal qualquer. Encontramos em Deleuze uma curiosa sequência conceitual: diferença, paradoxo, intensidade, profundidade ou spatium. $\mathrm{Na}$ individuação encontram-se diferentes graus da intensidade e diferentes naturezas da intensidade.

Vale notar o vocabulário de Simondon em torno do pré-individual, isto é, a presença de termos conceitos como ordem de magnitude, sistemas metaestáveis e energia potencial. Quanto a Deleuze, o uso do vocabulário da termodinâmica encontra-se em dinamismos espaço-temporais, processos intensivos de individuação, intensidade, magnitude intensiva e singularidades.

Com o objetivo de favorecer a compreensão daquilo que está em jogo em Síntese Assimétrica do Sensível, recorro ao artigo de Anne Sauvagnargues (2011), Simondon et la construction de l'empirisme transcendantal. A autora estabelece um conjunto de seis proposições para a construção do empirismo transcendental, curiosa expressão (conceito) a reunir o empirismo de Hume e o transcendental de Kant. A primeira afirma que a modulação das forças e dos materiais substitui a oposição da forma e da matéria. A segunda diz que toda individuação requer a existência de um estado metaestável, isto é, um estado de disparação. A terceira afirma que a individuação disparativa (díspar) permite uma nova teoria do problemático, que por sua vez substitui as concepções da dialética e da contradição. A quarta proposição, como já visto anteriormente, diz que a individuação emerge como resolução de uma diferença de potencial entre um meio pré-individual e uma singularidade. A quinta, que o signo resulta do acoplamento problemático entre realidades disparates (díspares), colocadas em ressonância. A última, por sua vez, afirma que a individuação vital, topológica e cronogenética, determina no plano do vivo, uma diferença entre exterior e interior, futuro e passado.

A modulação contribui na montagem do empirismo transcendental ao conectar-se com a problemática da forma intensiva e da hecceidade. Ela substitui a confrontação abstrata de matéria e forma pela variação intensiva de forças e dos materiais, como informação, que supõe a existência de um estado em equilíbrio metaestável. De acordo com SAUVAGNARGUES (2011), conceitos de Simondon reverberam em Deleuze. Disparação, axiomática, e em especial, a transdução, operação estruturante de diferenciação em todos os planos do real, físico, biológico, mental ou social. 
É a assimetria, a diferença problemática, que produz individuação, não como síntese, mas como resposta a uma situação metaestável. Na assimetria, produz-se soluções criativas, invenção de dimensões com novos sentidos. Sauvagnargues lembra os exemplos de Deleuze, individuação material do cristal e individuação vital da membrana. $\mathrm{O}$ exemplo simondoniano da cristalização é utilizado por Deleuze na definição do acontecimento (acontecimento como cristal, cristal de tempo, imagem-tempo).

Duas conclusões do artigo referido possibilitam aproximar individuação e subjetivação: na primeira, a definição simondoniana de individuação permite a Deleuze precisar sua filosofia da diferença, graças à definição do signo como disparação ${ }^{2}$. A segunda, as singularidades se produzem como as condições, a razão transcendental das individuações e das subjetivações humanas, e resume a gênese dos individuos e das pessoas ${ }^{3}$. (SAUVAGNARGUES, 2011, p.27).

Por outro lado, Simondon e Deleuze divergem quanto à transdução e quanto à diferença. Simondon pensa a transdução sob o regime de um processo de unificação, Deleuze a pensa sob a proeminência da heterogeneidade. Simondon pensa a diferença em termos de não identidade; Deleuze, como diferença afirmativa. O ser fasado de Simondon é diferente da multiplicidade substantiva de Deleuze.

Ponto de problematização: de que modo pode-se pensar processos de subjetivação levando em conta processos de individuação e singularidades pré-individuais? Considerando o pré-individual e a individuação, como tratar do problema da individuação psíquica, coletiva e maquínica? Por ora, questão pendente. A individuação psíquica é uma dilatação, uma expansão precoce da individuação vital).

Em Lógica do Sentido, também encontram-se alguns desdobramentos das ideias de Simondon, em especial o conceito do problemático. Ele remete ao acontecimento. Deleuze define o acontecimento como inatribuível a um sujeito, independe de pessoa ou ser. Ele não corresponde a uma cristalização, ao contrário, é molecular. $\mathrm{O}$ acontecimento se dá em uma vida, um verbo, um pôr-do-sol, próximo do infinitivo e da indeterminação.

\footnotetext{
${ }^{2}$ La définition simondienne de l'individuation permet à Deleuze de préciser sa Philosophie de la Différence, grâce à la définition du signe comme disparation.

${ }^{3}$ Ces singularités se produisent comme les conditions, la raison transcendantal des individuations et des subjectivations humaines et rendent compte de la genèse des individus et des personnes. 
A clínica, por exemplo, produz acontecimentos, ou pelo menos suas evidências sensíveis, ao desfazer os 'eus', ao entrar em processos novos de individuação, processos de indiferenciação, rumo ao neutro e ao singular, efeito ou desdobramento de um devir. $\mathrm{O}$ acontecimento está em relação direta com o jogo do virtual e do atual, desdobramento do fluxo problemático dos movimentos caóticos da vida.

Como nos estóicos, os acontecimentos se dão como modificações incorporais. Os efeitos incorporais se exprimem no infinitivo. Por outro, funciona como um conector entre corpo e linguagem. É incorporal mas não prescinde de sua materialidade. Efetua-se em coisas e estados de coisas e exprime-se na linguagem. Já o sentido, é neutro e impessoal, a individuação se dá por acontecimentos. São os acontecimentos que constituem os planos do vivido (fim da forma homem). Por último, a consistência do acontecimento dá-se pelo combate, ele cria individuações e singulariza.

Na Nona Série, 'Do Problemático', Deleuze enuncia que o modo do acontecimento é o problemático; as singularidades presidem a gênese das soluções de uma equação. O problema é determinado pelos pontos singulares que correspondem às séries, mas a pergunta é determinada por um processo aleatório que corresponde à casa vazia ou ao elemento móvel.

Na Décima Quinta Série, 'Das Singularidades', estas são caracterizadas como anônimas, nômades, impessoais, pré-individuais. Elas determinam o campo transcendental, impessoal e pré-individual. As singularidades presidem a gênese dos indivíduos e das pessoas, e se repartem em potenciais.

De acordo com Deleuze, as singularidades se organizam em um sistema metaestável, provido de energia potencial distribuída em séries. Elas gozam de um processo de auto unificação e frequentam a superfície, do tipo membrana ou superfície topológica de contato o mais profundo é a pele. A superfície é o lugar do sentido, nela ocorrem as atualizações da energia potencial.

O mundo do sentido tem por estatuto o problemático, como já vimos com Simondon. O sentido é a descoberta própria da filosofia transcendental. A definição deleuzeana das características do campo transcendental vale-se da análise de Simondon: energia potencial do campo, ressonância interna das séries, superfície topológica das membranas, organização do sentido, estatuto do problemático. 


\begin{abstract}
' $O$ vivo vive no limite de si mesmo, sobre seu limite... A polaridade característica da vida está ao nível da membrana; é neste terreno que a vida existe de maneira essencial, como um aspecto de uma tipologia dinâmica que mantém ela própria a metaestabilidade pela qual ela existe... Todo o conteúdo do espaço interior está topologicamente em contato com o conteúdo do espaço exterior sobre os limites do vivo; não há, com efeito, distância em topologia; toda a massa de matéria viva que está no espaço interior está ativamente presente ao mundo exterior sobre o limite do vivo... Fazer parte do meio de interioridade não significa somente estar dentro mas estar do lado interno do limite... Ao nível da membrana polarizada se enfrentam o passado interior e o futuro exterior...' (DELEUZE, 1974, pp.106-107; SIMONDON, 1964, pp.260-264).
\end{abstract}

Por último, compondo a ressonância produzida pela leitura deleuzeana de Simondon, encontram-se algumas passagens em Mil Platôs, especificamente no Platô intitulado A Geologia da Moral (Quem a terra pensa que é?). Deleuze retoma a questão do interior e do exterior no caso do cristal e do organismo, problematiza o papel do limite no caso da membrana, retoma os fenômenos de ressonância entre ordens de grandeza diferentes (molde, modulação e modelagem) e trabalha a noção de transdução, a partir da amplificação das ressonâncias entre o molar e o molecular.

\title{
3. Os Objetos Técnicos e a Cultura
}

O objeto técnico se define por um tipo de coerência que vem de suas propriedades, uma reciprocidade de ações causais e troca de informações em seu próprio funcionamento. Ele possui um modo de existência próprio e se define igualmente pelo processo de concretização e sobre determinação funcional que dá consistência a uma evolução. O objeto técnico contempla uma gênese que vai do abstrato ao concreto (CHATEAU, 2008). O artesanato é um exemplo de objeto técnico abstrato, ao passo que o objeto industrial é exemplo de objeto técnico concreto.

Os objetos técnicos e a cultura estão intrinsecamente ligados desde sempre. O descompasso entre a cultura técnica e a cultura humana, apontado por C. P. Snow na década de cinquenta do século passado, impôs uma compreensão parcial e precária dos objetos técnicos. A gênese e evolução do mundo técnico teve um primeiro momento de dependência do meio, aquele das ferramentas e instrumentos. Quando ocorre um destaque dos objetos em relação ao organismo, isto é, uma autonomia parcial, temos o momento dos utensílios e aparelhos. Na sequência, aparelhos e utensílios conquistam sua independência, através dos 
desenvolvimentos externo e interno. A realidade técnica e a realidade ambiental estão interligadas.

A oposição entre cultura e técnica não se sustenta ao longo da evolução histórica das técnicas: a pré-história ou fase mágica, as primeiras civilizações (escrita e metalurgia), a Grécia Antiga (filosofia da técnica e mitologia), o Império Romano (urbanismo e administração), a Idade Média (religião e surgimento das universidades), o Renascimento (racionalismo, empirismo, humanismo), a Revolução Industrial (máquinas), e a última fase, os séculos XX e XXI (informática, energias e biotecnologias). Ao longo de todo esse processo, os objetos técnicos e a cultura se mesclam e se redefinem a cada momento em sua gênese e evolução.

O mundo técnico dispõe de três níveis: o elemento, o indivíduo e o conjunto técnico. O otimismo do século XVIII justificava-se pela utilidade dos objetos. No século XIX intensifica-se a oposição no interior dos indivíduos técnicos, isto é, as máquinas: ora adversárias do humano, ora motores do progresso. O século XX coloca a informação como elemento determinante dos conjuntos técnicos: redes de comunicação, usinas, etc.

Dessa relação entre objetos técnicos e cultura, pode-se afirmar a temporalidade do objeto técnico. A gênese, a forma, o processo de individuação e a composição, são dependentes do tempo e da história. A modernidade sobrevalorizou a cultura científica em detrimento da cultura técnica; isto porque a concretização dos objetos está sujeita à redução do intervalo entre ciência e técnica. Causas técnicas predominam na evolução do objeto técnico, mas há também causas econômicas, sociais, políticas e psíquicas, além do intercâmbio de energia.

De acordo com Simondon (2001, 2005), pode-se estabelecer uma conexão entre invenção e essência técnica, através dos seguintes eixos:

- o ato de invenção constitui uma essência técnica;

- o objeto técnico ocupa um lugar intermediários entre o objeto natural e a representação científica;

- todo objeto técnico possui em alguma medida aspectos de abstração residuais;

- o objeto técnico existe em um meio misto, técnico-geográfico, que constitui a relação entre eles. 
Os esquemas da imaginação criadora humana antecipam o meio que tornará possível o funcionamento do objeto técnico. Rua de mão dupla que vai do imaginário, em especial do imaginário da ciência, ao retorno que atravessa os processos de subjetivação desencadeados na relação do homem com as máquinas. A individualidade técnica impõe uma singularização, uma diferenciação complexa que nos lança no trans-individual. De certa forma, trata-se aqui da transdução, operação complexa de individuação nos níveis físico, biológico, psíquico e coletivo. Eis porque a máquina se individua, seja ela de natureza técnica, psíquica, social, semiótica, ou quaisquer outras.

A imaginação científica e a prática científica se afetam mutuamente. Um exemplo dessa afirmativa encontramos nas relações da ciência com a literatura de ficção científica. Para Simondon, a tecnicidade é o grau de concretização do objeto. O objeto, ou um dispositivo, é apenas um elemento do mundo técnico, analogia que o autor faz para a relação entre o órgão em relação ao organismo.

Um objeto técnico atual, smartphone ou tablet, por exemplo, reúne o conjunto técnico oriundo da eletrônica e da informação, a economia do silício e dos materiais de composição, e a cultura do capitalismo onde essa se efetua na conexão virtual, subjetiva e financeira.

\section{Tecnologias e máquinas}

Gilles Deleuze e Félix Guattari caracterizam as máquinas como 'síntese de heterogêneos'. As máquinas são produzidas por descodificação e desterritorialização. Elas contém, entre seus componentes, matéria e energia, fluxos diagramáticos e algoritmos, componentes sociais, componentes de órgão, de influxo, de humor, informações, representações mentais individuais e coletivas (DELEUZE E GUATTARI, 2010).

A heterogeneidade maquínica confere uma existência, uma eficiência, uma potência de autoafirmação ontológica. Deleuze e Guattari referem-se a diversos registros da alteridade maquínica: alteridade de proximidade entre máquinas diferentes e entre peças de uma mesma máquina, alteridade de consistência material interna, alteridade de consistência formal diagramática, alteridade de phylum evolutivo, alteridade agônica entre máquinas de guerra e auto agônicas entre máquinas desejantes, que tendem ao próprio colapso, e, por fim, alteridade de escala ou fractal. 
Em O Anti-Édipo (2010), Deleuze e Guattari referem-se a dois tipos de máquinas: molares e moleculares. As primeiras subdividem-se em sociais, técnicas ou orgânicas. As máquinas moleculares são as máquinas desejantes, que por sua vez, podem ser formativas, cronógenas, e as máquinas propriamente ditas. As máquinas formativas dizem respeito ao funcionamento maquínico. As máquinas cronógenas são as máquinas agenciadas por ausência de liame, com ligações não localizáveis e dispersas. Quanto às máquinas propriamente ditas, elas procedem por fluxo e corte de fluxo, realizam conexões e disjunções em uma esquizogênese generalizada.

[...] As máquinas excedem toda mecânica. Opõem-se ao abstrato no seu sentido ordinário. As máquinas abstratas consistem em matérias não formadas e funções não formais. Cada máquina abstrata é um conjunto consolidado de matérias-funções (phylum e diagrama). Isto se vê claramente num plano tecnológico: um tal plano não é composto simplesmente por substâncias formadas, alumínio, plástico, fio elétrico, etc., mas por um conjunto de matérias não formadas que só apresentam graus de intensidade (resistência, condutibilidade, aquecimento, estiramento, velocidade ou retardamento, indução, transdução...), e funções diagramáticas que só apresentam equações diferenciais ou, mais geralmente, tensores. Certamente, no seio das dimensões do agenciamento, a máquina abstrata ou máquinas abstratas efetuam-se em formas e substâncias, com estados de liberdade variáveis. (DELEUZE E GUATTARI, 1997, p.227)

O contexto tecnológico atual reaproximou ciência e técnica. A conexão tecnociência e subjetividade produz novos modos de existência. Se a tecnociência se apresenta como a mais bem acabada concretização do capitalismo cognitivo contemporâneo, ela permite, por outro lado, um agenciamento singularizante dos modos de existência, que recoloca o problema político das relações entre tecnologia, máquina e vida. Uma das questões desse agenciamento é a relação entre corpos e máquinas.

A aproximação conceitual entre Gilbert Simondon e Gilles Deleuze cria uma linha de problematização acerca das tecnologias e das máquinas que libera o pensamento do embate entre tecnofóbicos e tecnofílicos. Esse pensamento passa por interface, incorporação, acoplagem e fusão. 


\section{A Individuação em 'The Erotic Life of Machines'}

A Vida Erótica das Máquinas é um vídeo realizado por Chris Cunningham, em parceria com a cantora Björk, produzido em 1999. Nele assistimos à montagem das peças de um robô que, ao ganhar vida, faz amor com uma outra máquina. As imagens são acompanhadas da música 'All Is Full Of Love', da própria cantora:

\footnotetext{
You'll be given love/You'll be taken care of/You'll be given love/You have to trust it Maybe not from the sources/You have poured yours/Maybe not from the directions/You are staring at

Twist your head around/It's all around you/All is full of love/ All around you All is full of love/You just aint receiving/All is full of love/Your phone is off the hook/All is full of love/Your doors are all shut/All is full of love

All is full of love/ All is full of love/ All is full of love/ All is full of love/ All is full of love (BJÖRK, Homogenic, 1997).
}

A princípio vê-se uma Björk deitada em um espaço que poderia ser uma clínica para robôs. Com a música, acompanha-se o deslocamento da montagem do robô para cenas de amor entre dois robôs. O que está em jogo no premiado vídeo permanentemente exposto no Museu de Arte Moderna de Nova York? Pode-se pensar na individuação das máquinas? Tratase de um novo regime de percepções e afetos? Ou mesmo dos devires pós-humanos?

As imagens contemplam uma espécie de ambivalência relativa ao corpo máquina. Como pode a máquina amar? Em jogo, a virtualização da existência humana. A música anula o caráter apocalíptico da reprodução de uma relação amorosa entre máquinas. A composição música imagens produz uma sensibilidade sinestésica, em uma sala asséptica, onde o tempo é eliminado, pois o corpo robô é reconstruído e o ritmo dos movimentos amorosos, reconstruído.

Simondon refere-se ao entusiasmo como aperfeiçoamento dos elementos técnicos; ele dá o exemplo da engrenagem em um automóvel, na esteira do desenvolvimento hoje temos o carro automático. Há um aperfeiçoamento do objeto técnico e, de certo modo, uma individuação técnica. Da mesma forma, pode-se pensar que o robô funcional de uma residência possa ser capaz de experimentar afetos e compor relações. Pode-se igualmente perguntar pela natureza destas relações, o que levaria a questão para o âmbito das relações entre imagem e experiência. 
Por outro lado, o problema da angústia, que a máquina talvez não seja capaz de experimentar, se considerarmos o atual cenário de desenvolvimento das pesquisas oriundas das convergências tecnológicas (bio-tecno-info-cogno), certamente é experimentado pelos humanos no encontro com as imagens do amor entre robôs. Elas produzem um corte na vida cotidiana, uma ruptura nos modos de vida, ou mesmo o colapso, tal como problematizado por Deleuze acerca do conto de Fitzgerald.

Entende-se que, do ponto de vista da individuação, o vídeo de Cunningham/Björk não produz alienação no sentido que Simondon atribui ao conceito, o de exterioridade das máquinas em relação ao humano; ao contrário, para quem está assistindo, a experiência é de uma pertença, algo da ordem de um acoplamento e sucessiva individuação, já que a máquina não prolonga o esquema corporal humano, mas recria outras funções e outros sentidos. A individuação de Simondon aproxima da subjetividade maquínica de Félix Guattari.

A individuação maquínica e sexual presente no vídeo é acompanhada da individuação sonora presente na voz que canta All Is Full Of Love. A voz, resquício do humano, compõe com o movimento dos robôs o agenciamento homem máquina. Esta composição é da ordem da individuação em seus diferentes níveis: física, pela matéria de que são compostos os robôs, isto é, os metais, as ligas, os fios, a água; psíquica e coletiva, através do psiquismo, do espírito, do sujeito - forma arcaica, mas que sobrevive; e até mesmo biológica, individuação presente através da voz que mantém o orgânico acoplado à máquina. Por último, vale dizer, 'A Vida Erótica das Máquinas' coloca em jogo a transindividualidade da hibridação humanomáquina, o cyborg e o andróide.

\section{Referências}

CHATEAU, Jean-Yves. Le Vocabulaire de Simondon. Paris: Ellipses Édition, 2008.

CUNNINGHAM, Chris, and BJÖRK. All Is Full Of Love (1999). Disponível em: https://www.youtube.com/watch?v=AjI2J2SQ528. Acesso em: 28 de agosto de 2015.

CUPANI, Alberto. Filosofia da Tecnologia: um convite. $2^{\mathrm{a}}$ Ed. Florianópolis: Ed. da UFSC, 2013. 
DELEUZE, Gilles. Diferença e Repetição. Tradução Luiz Benedito Lacerda Orlandi e Roberto Machado. Rio de Janeiro: Graal, 1988.

DELEUZE, Gilles. A Ilha Deserta: e outros textos. Organização da edição brasileira Luiz Benedito Lacerda Orlandi. São Paulo: Iluminuras, 2006.

DELEUZE, Gilles. Lógica do Sentido. Tradução Luiz Roberto Salinas Fortes. São Paulo: Perspectiva, 1974. (Estudos, 35).

DELEUZE, Gilles. Mil Platôs: Capitalismo e Esquizofrenia. Vol. 1. Tradução Aurélio Guerra Neto e Célia Pinto Costa. Rio de Janeiro: Ed. 34, 1995. (Coleção TRANS).

DELEUZE, Gilles e GUATTARI, Félix. O Anti-Édipo: capitalismo e esquizofrenia. Tradução Luiz Benedito Lacerda Orlandi. São Paulo: Ed. 34, 2010. (Coleção TRANS).

SAUVAGNARGUES, Anne. Simondon et la Construction de L'empirisme Transcendantal. IN: Cahiers Simondon Numéro 3. Sous la direction de Jean-Hugues Barthélémy. Paris: L'Harmattan, 2011.

SIMONDON, Gilbert. L'Individuation Psychique et Collective: à la lumière des notions de forme, information, potentiel e métastabilité. Paris: Éditions Aubier, 2007.

SIMONDON, Gilbert. L'Invention dans les Techniques: cours et conférences. Édition établie et présentée par Jean-Yves Chateau. Paris: Éditions du Seuil, 2005.

SIMONDON, Gilbert. Du Mode D'Existence des Objets Techniques. Paris: Éditions Aubier, 2001.

SNOW, Charles Percy. As Duas Culturas e Uma Segunda Leitura. Tradução Geraldo Gerson de Souza e Renato de Azevedo Rezende Neto. São Paulo: Editora da Universidade de São Paulo, 1995. 